\title{
The Function of Retinoid X Receptor $\alpha$ in Cancer Cells
}

\author{
Gui-Li Huang ${ }^{1}$, Qing-Xi Chen ${ }^{1}$ and Dong-Yan Shen ${ }^{2^{*}}$ \\ ${ }^{1}$ State Key Laboratory of Cellular Stress Biology, School of Life Sciences, Xiamen University' China \\ ${ }^{2}$ Biobank, The First Affiliated Hospital of Xiamen University, China
}

"Corresponding author: Dong-Yan Shen, No. 55, Road of Zhenhai, Siming Zone, Xiamen 361003, China, Tel: +86-592-2137507; Fax: +86-592-2137509; E-mail: shendongyan@163.com

Received date: July 01, 2016; Accepted date: July 25, 2016; Published date: August 03, 2016

Copyright: ๑ 2016 Huang GL, et al. This is an open-access article distributed under the terms of the Creative Commons Attribution License, which permits unrestricted use, distribution, and reproduction in any medium, provided the original author and source are credited

\begin{abstract}
The retinoid $X$ receptor $(R X R)$ is a member of the steroid/thyroid hormone superfamily of nuclear receptors (NRs) which are transcription factors that are essential in embryonic development, maintenance of differentiated phenotypes, metabolism and cell death. This review is to provide an overview of the mechanism of RXR $\alpha$ and $R X R \alpha$ signaling pathways involving RXR/TR3, RAR/RXR, PPAR/RXR, VDR/RXR, LXR/RXR, FXR/RXR in cancer cells and other diseases, which will enhance our ability to design rational therapeutic drugs for cancer. Recent studies have shown that an N-terminally truncated RXRa (tRXRa) exists in several cancer cell lines and primary tumors, which is considered as a kind of oncoprotein, demonstrating the new suitability of targeting tRXR $\alpha$ for cancer therapy.
\end{abstract}

Keywords: Retinoid X receptor $\alpha$; Cancer; Cancer therapy

\section{Introduction}

Nuclear receptors are a class of transcription factors that can directly bind to DNA and modulate target gene transcription. Nuclear receptors play key roles in reproduction, development, and homeostasis of organisms [1-3]. On the basis of their ligands, nuclear receptors are classified into three families. The first is the classic and most extensively characterized group, steroid- and thyroid-hormone receptors [1], including retinoid nuclear receptors. The second class is the orphan nuclear receptors, which are structurally related to nuclear hormone receptors but for which no ligand has yet been discovered. The third class of nuclear receptors is adopted orphan nuclear receptors, whose regulation has been shown to range from true ligandindependence to highly promiscuous ligand-dependence. The retinoid receptor subfamily contains two classes, namely, the retinoic acid receptors (RARs) and retinoid X receptors (RXRs). Each class consists of three subtypes ( $\alpha, \beta$ and $\gamma$ ) [4].

The structure of nuclear receptors is similar despite wide variation in ligand sensitivity. With few exceptions, they contain an NH2terminal region (also known as the $\mathrm{A} / \mathrm{B}$ region) that harbors a transactivation domain (AF-1); a core DNA-binding domain (the C region), also contains a dimerization interface that determines target gene specificity [5-7], containing two highly conserved zinc finger motifs that are common to the entire family except for dosage-specific sex reversal-adrenal hypoplasia congenita critical region on the $\mathrm{X}$ chromosome-1 (DAX1) and short heterodimeric partner (SHP) [8]; a hinge region (also named $\mathrm{D}$ region) that permits protein flexibility to allow for simultaneous receptor dimerization and DNA binding; and the $\mathrm{E}$ region, ligand-binding domain (LBD), contains a dimerization interface, and a ligand-dependent activation function (AF-2), The rest part is a variable $\mathrm{F}$ region whose entire function has not been known so far (Figure 1).

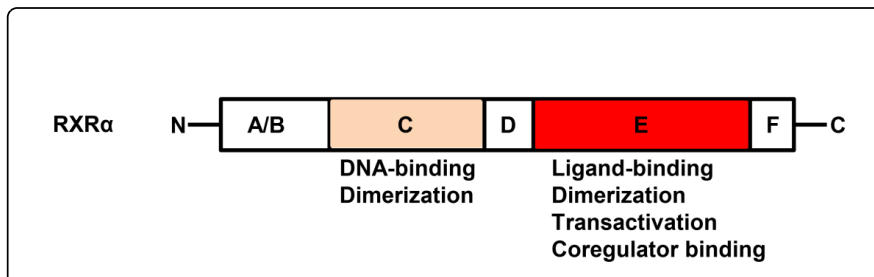

Figure 1: Schematic representation of RXRa.

Nuclear receptors are major targets for drug discovery and have key roles in development and homeostasis, as well as in many diseases such as cancer [8]. Retinoid X receptor a (RXRa) are becoming increasingly appreciated not simply as silent heterodimerization partners of other NRs, but also as therapeutic targets for cancer therapy and prevention by interacting with its ligands and several related signaling pathways. RXRa plays a role in many physiological processes including carcinogenesis [9]. Several RXRa ligands containing 9-cis-Retinoic acid (9-cis-RA), Targretin and the NSAID Etodolac and Sulindac could bind to RXRa to regulate different biological functions. One case of Retinoids' cancer therapy is that the effects of retinoid-based "differentiation therapy" have been impressively shown in the case of Acute Promyelocytic Leukaemia (APL) [10]. Genetic data also indicate that RXRa are involved in the chemopreventive activity of RA in experimental skin carcinogenesis [10]. It has been reported that targretin, a synthetic RXRa ligand, the major side effect of which is the induction of hypertriglyceridaemia, is recently used for treating persistent or refractory cutaneous $\mathrm{T}$ cell lymphoma $[9,11,12]$, indicating the possibility of targeting RXRa for cancer therapy (Table 1).

\begin{tabular}{|l|ll|}
\hline Cell type & $\begin{array}{l}\text { Available/Possible } \\
\text { Ligands) }\end{array}$ & Treatments(RXRa \\
\hline $\begin{array}{l}\text { Acute } \\
\text { Leukaemia }\end{array}$ & Promyelocytic & 9-cis-Retinoic acid \\
\hline
\end{tabular}




\begin{tabular}{|l|l|}
\hline kin carcinogenesis & 9-cis-Retinoic acid \\
\hline cutaneous T cell lymphoma & targretin \\
\hline
\end{tabular}

Table 1: Specific cancers and available/possible treatments targeting RXRa.

RXRa plays a central role in the regulation of many intracellular receptor signaling pathways and can mediate ligand-dependent transcription. RXRa enhances human cholangiocarcinoma growth via simultaneous activation of $\mathrm{Wnt} / \beta$-catenin and NF- $\kappa \mathrm{B}$ pathways [13]. The expression of the dominant-negative RXR affected the expression levels of a number of genes, some of which have been implicated in transcription, signal transduction, protein synthesis and protein trafficking [14]. The features of hepatocyte RXRa deletion in mice are that genes related to angiogenesis (Nos3, Kdr) were down-regulated, which leads to inhibition of angiogenesis, whereas genes connected with adipogenesis (Cebpb, Srebf1), pro-inflammatory pathway (NF$\kappa \mathrm{B}, \mathrm{TNF} \alpha$ ) and apoptosis (Gzmb, Bcl-2) were up-regulated [15]. RXR $\alpha$ is known to heterodimerise with a number of nuclear receptors including TR, RAR, PPAR, VDR, LXR, FXR and several orphan receptors [2,16,17]. So, RXRa ligands (agonists and antagonists) have the potential to affect the signaling of numerous other pathways. Many recent reviews have described the mechanisms of RXRa as heterodimerization partners in various circumstances including development, metabolic diseases, and cancer [18-25]. Here we will discuss the latest insights into these various mechanisms how RXRa interacts with other nuclear receptors in cancer and other diseases in order to develop improved target-based drugs for cancer and other disease therapy.

\section{RXRa Regulates TR3-Dependent Apoptosis by Modulating Its Nuclear Export and Mitochondrial Targeting}

TR3 (also known as Nur77 or NGFI-B), an orphan member of the nuclear receptor superfamily [26-28], is an immediate-early response gene whose expression is rapidly induced in response to a variety of extracellular stimuli [29], including growth factors, the phorbol ester 12-O-tetradecanoyl-13-phorbol acetate (TPA) and cyclic-AMPdependent pathways. The expression of TR3 is rapidly induced during apoptosis of immature thymocytes, T-cell hybridomas and various cancer cell types [28,30-34]. The apoptosis-associated translocation of TR3 from the nucleus to the cytoplasm has been observed in a lot of cancer cells such as lung cancer, ovarian cancer, colon cancer, gastric carcinoma and breast cancer [35-46]. RXRa is essential for nuclear export and mitochondrial targeting of TR3 through their dimerization interfaces located in their DNA-binding domain [43]. A nuclear export sequence (NES) present in RXRa's carboxyl-terminal region is required for the efficient nuclear export of RXR $/ \mathrm{TR} 3$ heterodimers [43]. RXRa has two dimerization interfaces, which are located in the DBD and the LBD [5,29]. The formation of the RXRa/TR3 heterodimer is mediated by dimerization interfaces in their DBDs, suggesting that the RXRa NES situating in the LBD is in its active conformation, resulting in the RXRa/TR3 heterodimer nuclear export [43]. Here RXR $\alpha$, acting as a helper factor, facilitates the translocation of TR3 from the nucleus to the mitochondria, inducing cytochrome $c$ release and cell apoptosis (Figure 2).

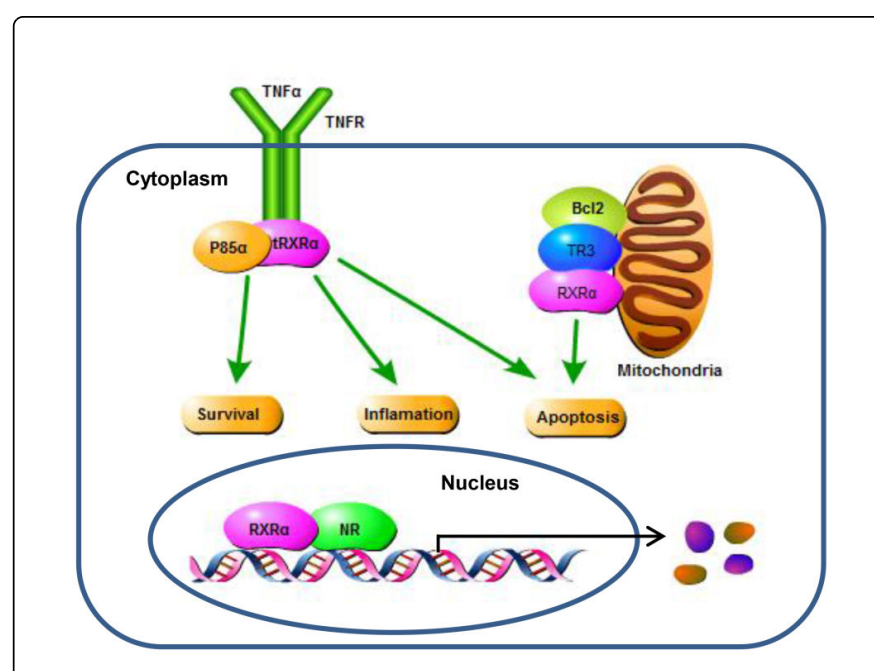

Figure 2: The actions of RXRa. RXRa heterodimerises with other nuclear receptors to regulate target genes. The cytoplasmic tRXRa through its interaction with $\mathrm{p} 85 a$ subunit of PI3K regulates cell survival, inflammation, and apoptosis. In addition, RXRa can target mitochondria through heterodimerization with TR3 to modulate mitochondria-dependent apoptosis.

RXR $\alpha$ ligands suppress apoptosis by preventing of TR3 and RXRa mitochondrial targeting. RXRa ligands 9-cis-RA and SR11237, for instance, effectively inhibited the release of cytochrome $c$ induced by TPA or SR11453 in LNCaP cells [43]. Ligand binding can favor RXRa/ Nur77 interaction to DNA binding and transactivation. The inhibition of RXRa/Nur77 DBD-mediated dimerization is related with the induction of heterodimer DNA binding and transactivation by 9-cisRA. Ligand binding allows RXRa to interact with Nur77 through their LBD dimerization interfaces, silencing the RXRa NES. The nuclear export of the RXRa/TR3 heterodimer may be suppressed by 9-cis-RA through its induction $\mathrm{RXR} \alpha$ homodimerization or modulation of RXRa/TR3 heterodimerization interfaces [43]. Accumulating evidence that RXRa ligands regulate apoptosis by modulating RXRa/TR3 heterodimer nuclear export in response to different apoptosis stimuli represents a novel approach for developing RXRa-based apoptosis regulators.

\section{Therapeutic Applications of RAR/RXR Heterodimer Modulators in Cancer}

Retinoic acid receptors (RARs) are ligand-inducible transcription factors that function as heterodimers with retinoid X receptors (RXRs) to regulate cell growth, differentiation, survival and death [47]. RXRs heterodimerizing with RARs in various tissues come into play mainly, if not exclusively [48]. These heterodimers have two distinct functions: First, they modulate the frequency of transcription initiation of target genes after binding to retinoic acid receptor response elements (RAREs) in their promoters; and second, they affect the efficiency of other signaling pathways ('crosstalk') [10]. RARs and RXRs form heterodimers, which are "non-permissive", that is unresponsive to RXR ligands on their own, but these agonists super activate transcription by synergizing with RAR ligands [21]. It is assumed that in these processes RAR heterodimerizes with RXR responding to RXR-selective 
ligands, which are inactive alone, strengthening by RAR-selective ligands [49].

Having a better understanding of the biological role of RARs and RXRs is beneficial in the design of selective receptor modulators that might overcome the limitations of current drugs. The panRAR-RXR agonist, 9-cis-retinoic acid (9cRA), an active metabolite of vitamin A, has a higher affinity to RXRa [50]. PanRXR-agonists can induce higher-order RXRa/RARs fusion hetero-oligomeric oncogenic complexes aberrantly recruit transcriptional co-repressors to downstream targets which are essential for transformation in acute promyelocytic leukemia [51], suggesting the pathological significance of their potential value as a therapeutic target. RXRa/RAR heterodimers play a role in the retinoid-stimulated increase in steroid sulfatase activity which was blocked by pharmacological inhibition of the RAF-1 and ERK MAP kinases [52]. Accumulating evidence that ligand-induced promoter activity of RXRa/RAR heterodimer is significantly suppressed by high glucose (HG) which promoted protein destabilization and serine-phosphorylation of RAR and RXR is mediated through oxidative stress/JNK signaling [53]. The impaired RXRa/RAR signaling and oxidative stress/JNK pathway forms a vicious circle, which significantly contributes to cardiomyocyte apoptosis induced by hyperglycemia [53]. The RXRa/RAR signaling pathway plays critical roles in hippocampal synaptic plasticity and greatly contributes to memory performance, and long-term potentiation (LTP) in the hippocampus in the adult brain [54]. RXRa/RAR signaling pathway also improves axonal regeneration and modulate reactions of glia cells in physiological reactions after spinal cord injury [55]. So the modulators of RXRa/RAR promise to be a useful target after spinal cord or brain lesions. A large amount of RARand RXR-selective ligands have been designed and the corresponding structural and functional analyses have provided deep insight into the molecular basis of ligand action, which is useful for drug discovery.

Delineation of the molecular mechanisms that regulate RXR specification and function should be important for understanding a number of diseases. The post-maturation apoptosis of HL60 leukaemia cells requires both retinoids and rexinoids via RXRa/RAR signaling pathway [8]. Retinoids inhibit the progression stage during chemical skin carcinogenesis. Structural overlap of a retinoic acid response element with these retinoid $\mathrm{X}$ response elements led to a high affinity of RXRa/RAR heterodimer to the retinoic acid response element in the p21 promoter, resulting in the prevention of RXR ligand-mediated p21 transactivation whose up-regulation facilitated G(1) arrest [56]. Recent studies revealed that LG1506, a selective RXR modulator, had a distinct mechanism of action in that it facilitated the co-repressors recruit to the RXRa/RAR heterodimer complex at target gene promoters, inhibiting the differentiation of hematopoietic stem cells (HSCs) in culture [57]. So, studies on the molecular basis and selectivity of the RXRa/RAR complexes that modulate various events during tumorigenesis, and their effect on differentiation and apoptogenic pathways, might provide ideas about promising avenues for efficacious cancer therapies. Further investigations will clarify the $\mathrm{RXRa/RAR-dependent} \mathrm{antitumor} \mathrm{activity} \mathrm{or} \mathrm{the} \mathrm{receptor-independent}$ anticancer action.

\section{Modulation of Permissive PPAR/RXR Heterodimers}

Peroxisome proliferator-activated receptors (PPARs) are liganddependent transcription factors, which can regulate gene expression by binding to peroxisome proliferator-responsive element (PPRE) located in the promoter region of their target genes as heterodimers with the
RXRs after ligand binding. PPARs that are involved in the regulation of energy homeostasis have recently drawn much attention as therapeutic targets. PPARs are comprised of three closely related isotypes (a, $\beta / \delta$ and $\gamma$ ), which are encoded by different genes. Recent studies have shown that PPAR $\gamma$ agonists can regulate differentiation and induce growth arrest and apoptosis in a variety of cancer types [58,59], which require RXRs as an obligate heterodimeric partner [60].

RXR $\alpha$ forms a permissive heterodimeric complex with PPAR $\gamma$ which activates PPAR regulated gene expression [61-63]. Thiazolidinediones (TZDs), which is one of the most important PPAR $\gamma$ agonists, inhibited cell proliferation of human bladder carcinoma cell lines by increasing cyclin-dependent kinase inhibitor expression and induced cell death [64], which also needs RXRa co-expressed. It has been reported that a number of combinations of the RXR $\alpha$ agonists with the PPAR $\gamma$ agonists are useful for treating various cancers. The combined treatment with the PPAR $\gamma$ ligand Rosiglitazone (BRL) and the RXR ligand 9-cis retinoic acid (9cRA) induces human breast cancer cells apoptosis [65]. The combination of the PPAR $\gamma$ ligand ciglitazone and the RXRa ligand 9-cis-retinoic acid (9cRA) by activation of the RXRa/PPAR $\gamma$ heterodimer is useful on inhibition of cell growth of human colon cancer cells [66]. The combination of rexinoids (synthetic retinoids specific for RXR) with PPAR ligands may enhance the antiproliferative effects [67], arguing for the evaluation of combination therapies. The combination of RXR agonists rexinoids and PPAR $\gamma$ agonists thiazolidinedione (TZD) represents novel therapeutic targets in melanoma [68]. The combination of the RXRa agonist, bexarotene, with the PPAR $\gamma$ agonist, rosiglitazone, has greater efficacy in growth inhibition than either single agent in colon cancer [69], suggesting a potential role for utilizing a combination regimen of an RXR $\alpha$ and PPAR $\gamma$ agonist for colon cancer. Combination therapies' advantage is that one drug may reverse a cancer-selective block of an antiproliferative signaling pathway, thus allowing the second to become active in cells that are otherwise resistant [70,71]. Therefore, the combined use of RXR $\alpha$ and PPAR $\gamma$ ligands may offer therapeutic strategies in the treatment of cancer.

Beyond the treatment of a variety of cancers, targeting RXRa/ $\operatorname{PPAR} \gamma$ heterodimer opens the way to novel therapeutic opportunities of other diseases. PPAR and RXRa play crucial role in transcription regulation of inflammation response. The expression of PPAR $\gamma$ and RXRa which have been recognized as crucial players in the pathogenesis of atherosclerosis was associated with a more pronounced disease progression in patients with advanced carotid atherosclerotic lesions [72]. More targeted modulation of function through ligands design has been proposed as a strategy to possibly overcome observed rexinoids side effects that have limited the use of these compounds in the treatment of metabolic diseases [21,73]. It is exciting options that the therapy of metabolic diseases originating from the synthesis of heterodimer-selective rexinoids for PPAR $\gamma / \mathrm{RXR} a$ combining with PPAR $\gamma$ agonists. It also deserves to be mentioned that co-administration of a rexinoid with a TZD produces enhance antidiabetic activity without the increase in triglycerides associated with rexinoid administration [74-76]. Anti-inflammatory properties of targeting PPAR $\gamma / \mathrm{RXR} \alpha$ are well documented in the periphery [55].

Further studies are required to investigate the molecular mechanisms by which PPAR $\gamma / \mathrm{RXR}$ a heterodimer ligands inhibit cell growth and induce differentiation. Extension of these results into the clinic may provide an opportunity to find a potentiated treatment effect of cancer, as well as other diseases, produced by the combination of PPAR $\gamma$ ligands with RXR $\alpha$ ligands. 


\section{RXR Dominates the Nuclear Import and Export of the Unliganded Vitamin D Receptor}

Liganded and unliganded vitamin D receptors (VDRs) carry out distinct functions, both of which require heterodimerization with retinoid X receptors (RXRs) [77]. Ligand-dependent functions of VDRs heterodimerizing with RXR regulate calcium homeostasis, immune functions, endocrine functions, vitamin D metabolism, and cellular differentiation [77]. Ligand binding induces conformational changes in the VDR, which promote heterodimerization with retinoid $\mathrm{X}$ receptor (RXR) and recruitment of a number of nuclear receptor coactivator proteins [78]. Ligand-independent activation of VDR/RXR heterodimers activates a reporter driven by the prolactin promoter, which is in the presence of Ets-1 that induces a conformational change in the receptor, which creates an active interaction surface with coactivators even in the AF2-defective mutants [79].

Many nuclear proteins shuttle between the cytoplasm and the nucleus. The steady-state nuclear localization of RXR and liganded VDR is mediated by means of the molecular mechanisms that the receptors shuttle between cytoplasm and nucleus, but the residence time in the nucleus is longer than in the cytoplasm [77]. After synthesis in the cytoplasm the import process of RXRs which can be promoted by liganded VDR is dependent on a nuclear localization sequence (NLS) in the DNA-binding domain (DBD) of RXR. RXRa increases the ligand-independent nuclear import of VDR. Both RXR $\alpha$ and VDR export require proteins of the export machinery. Unliganded VDR distributed evenly between the cytoplasm and the nucleus. VDR/RXR heterodimers through dimerization interfaces in the DNA-binding domain (DBD) of RXR $\alpha$ are formed in the cytoplasm and translocate together to the nucleus upon calcitriol (VDR ligand) binding [77].

In view of the above molecular mechanism that RXR dominates the nuclear import and export of the unliganded vitamin D receptor, it's worth noticing that the VDR/RXR heterodimer also plays a role in cancer. The effect that VDR ligand 1,25-dihydroxyvitamin D3 $(1,25(\mathrm{OH}) 2 \mathrm{D} 3)$ and its non-hypercalcemic analog, EB1089, decrease parathyroid hormone-related protein (PTHrP) mRNA and cellular protein levels which increase the growth and osteolytic potential of prostate cancer cells, is mediated via a negative Vitamin D response element (nVDRE) within the human PTHrP gene and involves an interaction between nVDREhPTHrP and the Vitamin D receptor (VDR) [80]. RXRa which is a frequent heterodimeric partner of the VDR forms part of the nuclear protein complex that interacts with nVDREhPTHrP along with the VDR in prostate cancer cells [80].

\section{The Interaction of RXR and Other Nuclear Receptor}

As the promiscuous partner of heterodimeric associations, RXRs play a key role within the Nuclear Receptor (NR) superfamily. The RXR contributes to the regulation of diverse biological pathways via its role as a heterodimeric partner of several nuclear receptors. Steroid and xenobiotic receptor (SXR) dimerizes with retinoid $\mathrm{X}$ receptor (RXR) and regulates the transcription of genes encoding xenobioticmetabolizing enzymes such as CYP3A4, which is activated by retinoids [81]. The human pregnane $\mathrm{X}$ receptor (hPXR) is an orphan nuclear receptor that binds to its response elements present in steroidinducible cytochrome $\mathrm{P}-450$ gene promoters, which requires the participation of RXR $\alpha$ [82]. It has been reported that a nuclear location of both hPXR and RXR in infiltrative breast cancer which is associated with an increased risk of recurrent disease [82]. Rexinoid bexarotene, a clinically used antitumoral agent, modulates triglycerides metabolism in plasma whose increase, the most frequent side-effect, is an independent risk factor of cardiovascular disease, but not cholesterol metabolism via a selective permissivity on target genes of the RXRa/LXR heterodimer in the liver [83]. The antitumoral agent bexarotene (Targretin, Bexarotene) regulates target genes by binding to the nuclear RXRa. The evidence has proven a favorable pharmacological effect of bexarotene on atherosclerosis despite the induction of hypertriglyceridemia, likely via a beneficial action on intestinal absorption and macrophage efflux [84]. RXRa/LXR heterodimer might contribute to the beneficial effects of rexinoids on atherosclerosis and warrant further evaluation of RXRa/LXR agonists in prevention and treatment of atherosclerosis. RXRa function as heterodimers with liver X receptors (LXRs), which are involved in glucose/lipid metabolism. All these findings indicate that RXRa is central to the regulation of many important physiological functions in the organism. This expands the number of possible pharmaceutical targets for intervention with RXR $\alpha$ agonists or antagonists.

\section{Regulation of tRXRa Production and Its Function}

RXRa regulates diverse biological functions. Except its well-known action in the nucleus, RXRa also have extranuclear actions. RXRa exists in the cytoplasm at different stages during development in certain cell types [85]. In response to differentiation [86], inflammation [87,88] and apoptosis [43], RXRa transfers from the nucleus to the cytoplasm. The truncated RXRa (tRXRa) proteins, only existing in the cytoplasm, are produced through limited proteolytic cleavage of RXRa in cancer cells [89,90]. The cytoplasmic fraction but not in the nucleus [89] was shown to contain proteases like cathepsin L-type protease and m-calpain [89-93] that cleaves RXRa at its amino terminus. The truncated RXRa is produced in tumor tissues but not in normal tissues [94] is in line with other findings that RXR $\alpha$ is cleaved in tumor but not in premalignant or normal tissues from patients with malignant human prostatic tumor [90] or thyroid cancer [93]. The 54 $\mathrm{kDa}$ full-length RXRa (fl-RXRa) protein level is often reduced in cancer cells and tumor tissues $[93,95]$, which is in part due to limited proteolytic processing of RXRa. Proteolytic processing of RXRa is an important mechanism in the regulation of the phosphatidylinositol-3$\mathrm{OH}$ kinase (PI3K)/Akt signaling pathway and provides its potential value as a therapeutic target.

The N-terminally truncated $44 \mathrm{kDa}$ RXRa protein and the $54 \mathrm{kDa}$ fl-RXR $\alpha$ protein play significant roles in various tissues with different effects. The extensive cytoplasmic tRXRa interacts with the p85a subunit of phosphatidylinositol-3-OH kinase (PI3K) to activate the PI3K/AKT survival pathway and induce anchorage-independent cell growth in vitro and tumor growth in animals (Figure 2) [94], conforming that tRXRa provide a therapeutic advantage in cancer treatment. Due to deletion of the N-terminal sequences, RXR $\alpha$ in several cancer cell lines and primary tumors confers its ability to interact with $\mathrm{p} 85 \mathrm{a}$. The p85a-binding motifs in RXRa are probably masked by the $\mathrm{N}$-terminal end sequences. The region, amino acids from 80 to 100 in RXR $\alpha$ critical for tRXRa binding to p85a [94], is enriched with proline resides, can presumably form several polyproline helices (PPII helix) known to bind to the SH3 domain [96] present in p85a. Cleavage of RXRa may represent a mechanism that triggers tRXRa signaling by removing the inhibitory $\mathrm{N}$-terminal domain, allowing tRXR $a$ to expose its p85a-binding motif. The tRXR $\alpha$ detected in the cytoplasm of cancer cells to modulate carcinogenesis acts nongenomically to activate the PI3K/AKT pathway to promote cancer cell growth and survival [94]. Hence, agents targeting tRXRa-mediated 
pathway can be effective. Nonsteroidal anti-inflammatory drugs (NSAIDs) sulindac could inhibit the tRXRa-dependent PI3K/AKT activation [94], suggesting that Sulindac stands for a type of anticancer drugs targeting this pathway. The tRXR $\alpha$ was critical for AKT activation by TNFa that could also activate PI3K/AKT signaling [97,98]. Transfection of RXRa siRNA, which inhibited both the expression of the fl-RXRa and the $44 \mathrm{kDa}$ tRXRa, significantly impaired the ability of TNFa to activate AKT [94]. Sulindac can lower tRXR $\alpha$-mediated activities that tRXR $\alpha$ contributes to the growth and survival of cancer cells by activating AKT, suggesting that tRXRa serves as an intracellular target mediating the apoptotic effect of Sulindac. The fact that sulindac and TNFa synergistically reduce tRXRa-mediated AKT activation [94] provides new understanding of the crosstalk between retinoid receptor and TNF $\alpha$ signaling pathways, implying the further tRXRa-based development for cancer therapy.

\section{Conclusion}

RXRs are obligatory DNA-binding partners for a number of nuclear receptors, broadening the spectrum of their biological activity to the corresponding nuclear receptor-signaling pathways. Unliganded RXRa self-associates into tetramers and that each dimer within these tetramers can separately bind to an RXRa response element which may bring about distant genomic effect. Ligand binding induces the dissociation of RXRa tetramers into dimers, which can alter gene expression by modulating the DNA structure. Many other nuclear receptors require $R X R a$ as heterodimerization partner for their function. This places RXRa in the crossroad of multiple distinct biological pathways. The emerging roles of RXR $\alpha$ in the RXR $\alpha$ signaling network and possible implications are helpful for our understanding of nuclear receptor biology and pharmacology. Thus the multiple roles that RXRa plays in all kinds of cells have turned RXRa into an attractive drug target. The priority is to change a tumorpromoting microenvironment to a tumor-inhibiting state and to understand the signaling mechanisms involved, finding a potential target for cancer prevention.

The unique property of RXRa dimerization interfaces allows cross talk among RXRa heterodimerization partners with respect to their subcellular localization and function. The RAR/RXR and PPAR/RXR signaling pathways have recently been implicated in the progression of neurodegenerative and psychiatric diseases, suggesting that the activation of PPAR/RXR and RAR/RXR transcription factors has been proposed as a therapeutic strategy in disorders of the central nervous system [99]. Overexpression of dominant negative RAR mutants may lead to repression of genes that are not normally targeted by corepressor-associated unliganded RAR/RXR heterodimers [100] and/or interfere with functions of other RXR heterodimeric partners through sequestration of RXRs. RXR-selective ligands (rexinoids) are valuable in the treatment of atherosclerosis, other cardiovascular indications and inflammatory diseases via pathways including the PPARs, the liver $\mathrm{X}$ receptors and the farnesoid X receptors [101-103]. RXRa ligands are attractive candidates for clinical application because of their activity against tamoxifen-resistant breast cancer, taxol-resistant lung cancer, metabolic syndrome, and allergy. This then led to investigation of the mechanism in which these compounds inhibited growth and the effects of combination treatment on essential cell growth and differentiation parameters in cancer. A detailed understanding of the multiple physiological effects elicited by various ligands through nuclear receptors is obviously good for drug discovery.
RXRa has been implicated in several neoplastic diseases. Ligands that activate the nuclear RXRa display potent anti-carcinogenic activities through the mechanisms by which these ligands inhibit carcinoma cell growth and promote apoptosis. The case that RXRa ligands inhibit mammary carcinoma cell growth stems from the ability of these ligands to regulate the state of RXRa and is independent of the direct intrinsic transcriptional activity of the receptor [104]. Some combined compounds that target RAR/RXR, RXR/TR3, PPAR/RXR, VDR/RXR, RXR/LXR, RXR/FXR, etc. heterodimers are powerful anticancer drugs. An improved understanding of the mechanism of these heterodimers pathway should enable the rational design of more selective modulators in general. Combinatorial treatments might lead to synergistic effects on growth control or induction of apoptosis, thereby allowing the use of lower concentrations as well as maintaining efficacy and reducing side effects. It has been reported that RXRa ligands such as 9-cis-RA, Targretin, Etodola and Sulindac play a significant role in a lot of cancer therapy, whether alone or combing with its partners' ligands. RXR $\alpha$ and its partner present main targets for pharmacologic interventions, allowing development of therapies targeting different receptors with high efficiency. The combined use of several compounds that act on different signalling pathways also represents an interesting approach in curing cancer. The combination of retinoids and T-cell-based immunotherapy has efficacy in neuroblastoma. The reason why addition of the HDAC inhibitor sodium phenyl butyrate in the treatment of a patient with multiple relapsed RAresistant APL resulted in complete remission [105], is that HDAC inhibitor sensitized the RAinsensitive cells to the differentiative action of RA by restoring retinoid signaling [70].

RXRa plays a central role in controlling multiple hormonal pathways through heterodimerization. Despite their promiscuity in heterodimer formation and activation of multiple pathways, RXRa is a target for drug discovery. Recent studies have shed light on the molecular mechanisms underlying tRXR $\alpha$ action, which has made it possible to design appropriate modulators for cancer therapy. Further studies are required to understand the regulation of tRXRa in all kinds of tissues in order to have far insight in the pathological function of tRXRa. It has been shown that the presence of tRXR $a$ in breast and liver cancer tissues but not in tumor surrounding tissues or distant normal tissues from the same patients. The RXRa-selective Sulindac derivative K-80003 could effectively inhibit the tRXRa pathway and the growth of cancer cells in vitro and in animals, providing an important new treatment for cancer patients.

The accumulated knowledge of the mechanistic, molecular and pharmacological actions of RXRa ligands is the basis for the development of efficient anticancer therapies. Indeed, it has been shown that retinoid agonists can autonomously induce rapid apoptosis under certain conditions [106]. RXRa is an attractive molecular target for drug development. The rational drug design can develop new RXR $\alpha$ selective ligands rexinoids with improved biological properties, warranting further development for cancer therapy. This can be achieved only by interdisciplinary efforts that combine in vivo analysis using genetically engineered animals with in vitro cell and molecular biological analyses to elucidate the detailed mechanisms that drugs promote cancer cells apoptosis by RXRa signaling pathways. This unique class of RXR ligands will provide a means to control distinct target genes at the level of transcription and allow the development of retinoids with a new pharmacological action.

Additional mechanisms to regulate RXRa might also exist. It will be interesting to examine the significance of RXRa signaling pathway. The 
complete understanding of RXRa-dependent mechanism and drugs design targeting RXRa signaling for various diseases is therefore a major challenge for future research. There is no doubt that RXRa is important to cancer biology and treatment in the 21 st century. It is going to continue investigating the possible involvement of various RXRa regulators in cancer cells and the molecular mechanisms that are involved. Such studies will provide useful information for the design of therapeutic drugs. Obviously, studies on the regulation of RXRa signaling will remain both challenging and exciting in years to come.

\section{Acknowledgement}

This work was supported by Grants from the National Nature Science Foundation of China (81572394) and the National Science Foundation for Fostering Talents in Basic Research of the National Natural Science Foundation of China (J1310027).

\section{References}

1. Evans RM (1988) The steroid and thyroid hormone receptor superfamily. Science 240: 889-895.

2. Mangelsdorf DJ, Thummel C, Beato M, Herrlich P, Schutz G, et al. (1995) The nuclear receptor superfamily: The second decade. Cell 83: 835-839.

3. Kastner P, Mark M, Chambon P (1995) Non-steroid nuclear receptors: what are genetic studies telling us about their role in real life? Cell 83: 859-869.

4. Cavasotto CN, Liu G, James SY, Hobbs PD, Peterson VJ, et al. (2004) Determinants of retinoid $\mathrm{X}$ receptor transcriptional antagonism. J Med Chem 47: 4360-4372.

5. Perlmann T, Umesono PNK, Rangarajan BM, Forman, Evans RM (1996) Two distinct dimerization interfaces differentially modulate target gene specificity of nuclear hormone receptors. Mol Endocrinol 10: 958-966.

6. Zechel C, Shen XQ, Chen JY, Chen ZP, Chambon P, et al. (1994) The dimerization interfaces formed between the DNA binding domains of RXR, RAR and TR determine the binding specificity and polarity of the full-length receptors to direct repeats. EMBO J 13: 1425-1433.

7. Rastinejad F, Wagner T, Zhao Q, Khorasanizadeh S (2000) Structure of the RXR-RAR DNA-binding complex on the retinoic acid response element DR1. EMBO J 19: 1045-1054.

8. Gronemeyer H, Gustafsson JA, Laudet V (2004) Principles for modulation of the nuclear receptor superfamily. Nat Rev Drug Discov 3: 950-964.

9. Dawson MI, Zhang XK (2002) Discovery and design of retinoic acid receptor and retinoid $\mathrm{X}$ receptor class- and subtype-selective synthetic analogs of all-trans-retinoic acid and 9-cis-retinoic acid. Cur Med Chem 9:623-637.

10. Altucci L, Gronemeyer H (2001) The promise of retinoids to fight against cancer. Nat Rev Cancer 1: 181-193.

11. Kempf W, Kettelhack N, Duvic M, Burg G (2003) Topical and systemic retinoid therapy for cutaneous T-cell lymphoma. Hematol Oncol Clin North Am 17: 1405-1419.

12. Zhang C, Duvic M (2003) Retinoids: Therapeutic applications and mechanisms of action in cutaneous T-cell lymphoma. Dermatol Ther 16: 322-330.

13. Huang GL, Zhang W, Ren HY, Shen XY, Chen QX, et al (2015) Retinoid X receptor alpha enhances human cholangiocarcinoma growth through simultaneous activation of Wnt/beta-catenin and nuclear factor-kappaB pathways. Cancer Sci 106: 1515-1523.

14. Miyazaki S, Taniguchi H, Moritoh Y, Tashiro F, Yamamoto T, et al. (2010) Nuclear hormone retinoid $\mathrm{X}$ receptor (RXR) negatively regulates the glucose-stimulated insulin secretion of pancreatic ss-cells. Diabetes 59: 2854-2861.
15. Razny U, Wator L, Polus A, Wan YJ, Dyduch G, et al. (2009) Hepatocyte RXR alpha deletion in mice leads to inhibition of angiogenesis. Genes Nutr 4: 69-72.

16. Giguère V (1999) Orphan nuclear receptors: from gene to function. Endocr Rev 20: 689-725.

17. Chambon P (1996) A decade of molecular biology of retinoic acid receptors. FASEB J 10: 940-954.

18. Mark M, Ghyselinck NB, Chambon P (2006) Function of retinoid nuclear receptors: Lessons from genetic and pharmacological dissections of the retinoic acid signaling pathway during mouse embryogenesis. Annu Rev Pharmacol Toxicol 46: 451-480.

19. Germain P, Chambon P, Eichele G, Evans RM, Lazar MA, et al (2006) International Union of Pharmacology. LXIII. Retinoid X receptors. Pharmacol Rev 58:760-772.

20. Metzger D, Chambon P (2007) Contribution of targeted conditional somatic mutagenesis to deciphering retinoid $\mathrm{X}$ receptor functions and to generating mouse models of human diseases. Handb Exp Pharmacol 21: 511-524.

21. Pérez E, Bourguet W, Gronemeyer H, de Lera AR (2012) Modulation of RXR function through ligand design. Biochim Biophys Acta 1821: 57-69.

22. Desvergne B (2007) RXR: from partnership to leadership in metabolic regulations. Vitam Horm 75: 1-32.

23. Altucci L, Leibowitz MD, Ogilvie KM, de Lera AR, Gronemeyer H (2007) RAR and RXR modulation in cancer and metabolic disease. Nat Rev Drug Discov 6: 793-810.

24. Pinaire JA, Reifel-Miller A (2007) Therapeutic potential of retinoid x receptor modulators for the treatment of the metabolic syndrome. PPAR Res 2007: 94156.

25. Lefebvre P, Benomar Y, Staels B (2010) Retinoid X receptors: Common heterodimerization partners with distinct functions. Trends Endocrinol Metab 21: 676-683.

26. Chang C, Kokontis J, Liao SS, Chang Y (1989) Isolation and characterization of human TR3 receptor: A member of steroid receptor superfamily. J Steroid Biochem 34: 391-395.

27. Hazel TG, Nathans D, Lau LF (1988) A gene inducible by serum growth factors encodes a member of the steroid and thyroid hormone receptor superfamily. Proc Natl Acad Sci USA 85: 8444-8448.

28. Milbrandt J (1988) Nerve growth factor induces a gene homologous to the glucocorticoid receptor gene. Neuron 1: 183-188.

29. Zhang XK (2002) Vitamin A and apoptosis in prostate cancer. Endocr Relat Cancer 9: 87-102.

30. Liu ZG, Smith SW, McLaughlin KA, Schwartz LM, Osborne BA (1994) Apoptotic signals delivered through the T-cell receptor of a T-cell hybrid require the immediate-early gene nur77. Nature 367: 281-284.

31. Woronicz JD, Calnan B, Ngo V, Winoto A (1994) Requirement for the orphan steroid receptor Nur77 in apoptosis of T-cell hybridomas. Nature 367: 277-281.

32. Li Y, Lin B, Agadir A, Liu R, Dawson MI, et al. (1998) Molecular determinants of AHPN (CD437)-induced growth arrest and apoptosis in human lung cancer cell lines. Mol Cell Biol 18: 4719-4731.

33. Li H, Kolluri SK, Gu J, Dawson MI, Cao X, et al. (2000) Cytochrome c release and apoptosis induced by mitochondrial targeting of nuclear orphan receptor TR3. Science 289: 1159-1164.

34. Uemura H, Chang C (1998) Antisense TR3 orphan receptor can increase prostate cancer cell viability with etoposide treatment. Endocrinology 139: 2329-2334.

35. Dawson MI, Hobbs PD, Peterson VJ, Leid M, Lange CW, (2001) Apoptosis induction in cancer cells by a novel analogue of 6-[3-(1adamantyl)-4-hydroxyphenyl]-2-naphthalenecarboxylic acid lacking retinoid receptor transcriptional activation activity. Cancer Res 61: 4723-4730.

36. Holmes WF, Soprano DR, Soprano KJ (2002) Elucidation of molecular events mediating induction of apoptosis by synthetic retinoids using a CD437-resistant ovarian carcinoma cell line. J Biol Chem 277: 45408-45419. 
37. Holmes WF, Soprano DR, Soprano KJ (2003) Comparison of the mechanism of induction of apoptosis in ovarian carcinoma cells by the conformationally restricted synthetic retinoids CD437 and 4-HPR. J Cell Biochem 89: 262-278.

38. Liu S, Wu Q, Ye XF, Cai JH, Huang ZW, et al. (2002) Induction of apoptosis by TPA and VP-16 is through translocation of TR3. World J Gastroenterol 8: 446-450.

39. Wu Q, Liu S, Ye XF, Huang ZW, Su WJ (2002) Dual roles of Nur77 in selective regulation of apoptosis and cell cycle by TPA and ATRA in gastric cancer cells. Carcinogenesis 23:1583-1592.

40. Jeong JH, Park JS, Moon B, Kim MC, Kim JK, et al. (2003) Orphan nuclear receptor Nur77 translocates to mitochondria in the early phase of apoptosis induced by synthetic chenodeoxycholic acid derivatives in human stomach cancer cell line SNU-1. Ann N Y Acad Sci 1010: 171-177.

41. Kolluri SK, Bruey-Sedano N, Cao X, Lin B, Lin F, et al. (2003) Mitogenic effect of orphan receptor TR3 and its regulation by MEKK1 in lung cancer cells. Mol Cell Biol 23: 8651-8667.

42. Wilson AJ, Arango D, Mariadason JM, Heerdt BG, Augenlicht LH (2003) TR3/Nur77 in colon cancer cell apoptosis. Cancer Res 63: 5401-5407.

43. Cao X, Liu W, Lin F, Li H, Kolluri SK, et al. (2004) Retinoid X receptor regulates Nur77/thyroid hormone receptor 3-dependent apoptosis by modulating its nuclear export and mitochondrial targeting. Molecular and Cellular Biology 24: 9705-9725.

44. Jacobs CM, Boldingh KA, Slagsvold HH, Thoresen GH, Paulsen RE (2004) ERK2 prohibits apoptosis-induced subcellular translocation of orphan nuclear receptor NGFI-B/TR3. J Biol Chem 279: 50097-50101.

45. Lee KW, Ma L, Yan X, Liu B, Zhang XK, et al. (2005) Rapid apoptosis induction by IGFBP-3 involves an insulin-like growth factor-independent nucleomitochondrial translocation of RXRalpha/Nur77. J Biol Chem 280: 16942-16948.

46. Lin B, Kolluri SK, Lin F, Liu W, Han YH, et al. (2004) Conversion of Bcl-2 from protector to killer by interaction with nuclear orphan receptor Nur77/TR3. Cell 116: 527-540.

47. le Maire A, Alvarez S, Shankaranarayanan P, Lera AR, Bourguet W, et al. (2012) Retinoid receptors and therapeutic applications of RAR/RXR modulators. Curr Top Med Chem 12: 505-527.

48. Kastner P (1997) Genetic evidence that the retinoid signal is transduced by heterodimeric RXR/RAR functional units during mouse development Development 124: 313-326.

49. Chen JY, Clifford J, Zusi C, Starrett J, Tortolani D, et al. (1996) Two distinct actions of retinoid-receptor ligands. Nature 382: 819-822.

50. Kane MA (2012) Analysis, occurrence, and function of 9-cis-retinoic acid. Biochim Biophys Acta 1821: 10-20.

51. Zeisig BB, Kwok C, Zelent A, Shankaranarayanan P, Gronemeyer H, et al. (2007) Recruitment of RXR by homotetrameric RARalpha fusion proteins is essential for transformation. Cancer Cell 12: 36-51.

52. Hughes PJ, Zhao Y, Chandraratna RA, Brown G (2006) Retinoidmediated stimulation of steroid sulfatase activity in myeloid leukemic cell lines requires RARalpha and RXR and involves the phosphoinositide 3 kinase and ERK-MAP kinase pathways. J Cell Biochem 97: 327-350.

53. Singh AB, Guleria RS, Nizamutdinova IT, Baker KM, Pan J (2012) High glucose-induced repression of RAR/RXR in cardiomyocytes is mediated through oxidative stress/JNK signaling. J Cell Physiol 227: 2632-2644.

54. Nomoto M, Takeda Y, Uchida S, Mitsuda K, Enomoto H, et al. (2012) Dysfunction of the RAR/RXR signaling pathway in the forebrain impairs hippocampal memory and synaptic plasticity. Mol Brain 5: 8

55. Van Neerven S, Mey J (2007) RAR/RXR and PPAR/RXR Signaling in Spinal Cord Injury. PPAR Res 2007: 29275.

56. Tanaka T, Suh KS, Lo AM, De Luca LM (2007) p21WAF1/CIP1 is a common transcriptional target of retinoid receptors: Pleiotropic regulatory mechanism through retinoic acid receptor (RAR)/retinoid X receptor (RXR) heterodimer and RXR/RXR homodimer. J Biol Chem 282: 29987-29997.

57. Safi R, Muramoto GG, Salter AB, Meadows S, Himburg H, et al. (2009) Pharmacological manipulation of the RAR/RXR signaling pathway maintains the repopulating capacity of hematopoietic stem cells in culture. Mol Endocrinol 23: 188-201.

58. Grommes C, Landreth GE, Heneka M (2004) Antineoplastic effects of peroxisome proliferator-activated receptor gamma agonists. Lancet Oncol 5: 419-429.

59. Michalik L, Auwerx J, Berger JP, Chatterjee VK, Glass CK, et al. (2006) International Union of Pharmacology. LXI. Peroxisome proliferatoractivated receptors. Pharmacol Rev 58: 726-741.

60. Ziouzenkova O, Plutzky J (2008) Retinoid metabolism and nuclear receptor responses: New insights into coordinated regulation of the PPAR-RXR complex. FEBS Lett 582: 32-38.

61. Lala DS, Mukherjee R, Schulman IG, Koch SS, Dardashti LJ, et al. (1996) Activation of specific RXR heterodimers by an antagonist of RXR homodimers. Nature 383: 450-453.

62. Kliewer SA, Forman BM, Blumberg B, Ong ES, Borgmeyer U, et al. (1994) Differential expression and activation of a family of murine peroxisome proliferator-activated receptors. Proc Natl Acad Sci U S A 91: 7355-7359.

63. Cesario RM, Klausing K, Razzaghi H, Crombie D, Rungta D, et al. (2001) The rexinoid LG100754 is a novel RXR:PPARgamma agonist and decreases glucose levels in vivo. Mol Endocrinol 15: 1360-1369.

64. Guan YF, Zhang YH, Breyer RM, Davis L, Breyer MD (1999) Expression of peroxisome proliferator-activated receptor gamma (PPARgamma) in human transitional bladder cancer and its role in inducing cell death. Neoplasia 1: 330-339.

65. Bonofiglio D, Cione E, Vizza D, Perri M, Pingitore A, et al. (2011) Bid as a potential target of apoptotic effects exerted by low doses of PPARgamma and RXR ligands in breast cancer cells. Cell Cycle 10: 2344-2354.

66. Yamazaki K, Shimizu M, Okuno M, Matsushima-Nishiwaki R, Kanemura $\mathrm{N}$, et al. (2007) Synergistic effects of RXR alpha and PPAR gamma ligands to inhibit growth in human colon cancer cells--phosphorylated RXR alpha is a critical target for colon cancer management. Gut 56:1557-1563.

67. Crowe DL, Chandraratna RA (2004) A retinoid X receptor (RXR)selective retinoid reveals that RXR-alpha is potentially a therapeutic target in breast cancer cell lines and that it potentiates antiproliferative and apoptotic responses to peroxisome proliferator-activated receptor ligands. Breast Cancer Res 6: 546-555.

68. Klopper JP, Sharma V, Bissonnette R, Haugen BR (2010) Combination PPARgamma and RXR agonist treatment in melanoma cells: Functional importance of S100A2. PPAR Res 2010: 729876.

69. Cesario RM, Stone J, Yen WC, Bissonnette RP, Lamph WW (2006) Differentiation and growth inhibition mediated via the RXR:PPARgamma heterodimer in colon cancer. Cancer Lett 240: 225-233.

70. Ferrara FF, Fazi F, Bianchini A, Padula F, Gelmetti V, et al (2001) Histone deacetylase-targeted treatment restores retinoic acid signaling and differentiation in acute myeloid leukemia. Cancer Res 61: 2-7.

71. Altucci L, Rossin A, Hirsch O, Nebbioso A, Vitoux D, et al (2005) Rexinoid-triggered differentiation and tumor-selective apoptosis of acute myeloid leukemia by protein kinase A-mediated desubordination of retinoid X receptor. Cancer Res 65: 8754-8765.

72. Giaginis C, Klonaris C, Katsargyris A, Kouraklis G, Spiliopoulou C, et al (2011) Correlation of peroxisome proliferator-activated receptor-gamma (PPAR-gamma) and retinoid X receptor-alpha (RXR-alpha) expression with clinical risk factors in patients with advanced carotid atherosclerosis. Med Sci Monit 17: CR381-391.

73. Deng T, Shan S, Li ZB, Wu ZW, Liao CZ, et al. (2005) A new retinoid-like compound that activates peroxisome proliferator-activated receptors and lowers blood glucose in diabetic mice. Biol Pharm Bull 28:1192-1196.

74. Mukherjee R, Davies PJ, Crombie DL, Bischoff ED, Cesario RM, et al (1997) Sensitization of diabetic and obese mice to insulin by retinoid X receptor agonists. Nature 386: 407-410.

75. Leibowitz MD, Ardecky RJ, Boehm MF, Broderick CL, Carfagna MA, et al. (2006) Biological characterization of a heterodimer-selective retinoid $\mathrm{X}$ receptor modulator: Potential benefits for the treatment of type 2 diabetes. Endocrinology 147: 1044-1053. 
Page 8 of 8

76. Forman BM (2002) The anti-diabetic agent LG100754 sensitizes cells to low concentrations of peroxisome proliferator-activated receptor gamma ligands. J Biol Chem 277:12503-12506.

77. Prufer K (2002). Retinoid X receptor dominates the nuclear import and export of the unliganded vitamin D receptor. Molecular Endocrinology 16: $1738-1751$.

78. MacDonald PN, Baudino TA, Tokumaru H, Dowd DR, Zhang C (2001) Vitamin D receptor and nuclear receptor co-activators: Crucial interactions in vitamin D-mediated transcription. Steroids 66: 171-176.

79. Tolon RM, Castillo AI, Jimenez-Lara AM, Aranda A (2000) Association with Ets-1 causes ligand- and AF2-independent activation of nuclear receptors. Mol Cell Biol 20: 8793-8802.

80. Sepulveda VA, Weigel NL, Falzon M (2006). Prostate cancer cell typespecific involvement of the VDR and RXR in regulation of the human PTHrP gene via a negative VDRE. Steroids 71: 102-115.

81. Wang K, Mendy AJ, Dai G, Luo HR, He L, et al. (2006) Retinoids activate the RXR/SXR-mediated pathway and induce the endogenous CYP3A4 activity in Huh7 human hepatoma cells. Toxicol Sci 92: 51-60.

82. Conde I, Lobo MV, Zamora J, Perez J, Gonzalez FJ, et al. (2008) Human pregnane $\mathrm{X}$ receptor is expressed in breast carcinomas, potential heterodimers formation between hPXR and RXR-alpha. BMC Cancer 8: 174.

83. Lalloyer F, Pedersen TA, Gross B, Lestavel S, Yous S, et al. (2009) Rexinoid bexarotene modulates triglyceride but not cholesterol metabolism via gene-specific permissivity of the RXR/LXR heterodimer in the liver. Arterioscler Thromb Vasc Biol 29: 1488-1495.

84. Lalloyer F, Fievet C, Lestavel S, Torpier G, van der Veen J, et al. (2006) The RXR agonist bexarotene improves cholesterol homeostasis and inhibits atherosclerosis progression in a mouse model of mixed dyslipidemia. Arterioscler Thromb Vasc Biol 26: 2731-2737.

85. Fukunaka K, Saito T, Wataba K, Ashihara K, Ito E, et al. (2001) Changes in expression and subcellular localization of nuclear retinoic acid receptors in human endometrial epithelium during the menstrual cycle. Mol Hum Reprod 7: 437-446.

86. Katagiri Y, Takeda K, Yu ZX, Ferrans VJ, Ozato K, et al. (2000) Modulation of retinoid signalling through NGF-induced nuclear export of NGFI-B. Nat Cell Biol 2: 435-440.

87. Ghose R, Zimmerman TL, Thevananther S, Karpen SJ (2004) Endotoxin leads to rapid subcellular re-localization of hepatic RXRalpha: A novel mechanism for reduced hepatic gene expression in inflammation. Nucl Recept 2: 4 .

88. Zimmerman TL, Thevananther S, Ghose R, Burns AR, Karpen SJ (2006) Nuclear export of retinoid $\mathrm{X}$ receptor alpha in response to interleukin-1beta-mediated cell signaling: Roles for JNK and SER260. J Biol Chem 281: 15434-15440.

89. Nagaya T, Murata Y, Yamaguchi S, Nomura Y, Ohmori S, et al. (1998) Intracellular proteolytic cleavage of 9-cis-retinoic acid receptor alpha by cathepsin L-type protease is a potential mechanism for modulating thyroid hormone action. J Biol Chem 273: 33166-33173.

90. Zhong C, Yang S, Huang J, Cohen MB, Roy-Burman P (2003) Aberration in the expression of the retinoid receptor, RXRalpha, in prostate cancer. Cancer Biol Ther 2: 179-184.
91. Matsushima-Nishiwaki R, Shidoji Y, Nishiwaki S, Moriwaki H, Muto Y (1996) Limited degradation of retinoid X receptor by calpain. Biochem Biophys Res Commun 225: 946-951.

92. Nomura Y, Nagaya T, Yamaguchi S, Katunuma N, Seo H (1999). Cleavage of RXRalpha by a lysosomal enzyme, cathepsin L-type protease. Biochem Biophys Res Commun 254: 388-394.

93. Takiyama Y (2004). Decreased expression of retinoid X receptor isoforms in human thyroid carcinomas. Journal of Clinical Endocrinology and Metabolism 89: 5851-5861.

94. Zhou H, Liu W, Su Y, Wei Z, Liu J, et al. (2010) NSAID Sulindac and its analog bind RXRa and inhibit RXRa-dependent AKT signaling. Cancer Cell 17: 560-573.

95. Picard E, Seguin C, Monhoven N, Rochette-Egly C, Siat J, et al. (1999) Expression of retinoid receptor genes and proteins in non-small-cell lung cancer. J Natl Cancer Inst 91: 1059-1066.

96. Kaneko T, Li L, Li SS (2008) The SH3 domain--a family of versatile peptide- and protein-recognition module. Front Biosci 13: 4938-4952.

97. Ozes ON, Mayo LD, Gustin JA, Pfeffer SR, Pfeffer LM, et al. (1999) NFkappaB activation by tumour necrosis factor requires the Akt serinethreonine kinase. Nature 401: 82-85.

98. Pincheira R, Castro AF, Ozes ON, Idumalla PS, Donner DB (2008) Type 1 TNF receptor forms a complex with and uses Jak2 and c-Src to selectively engage signaling pathways that regulate transcription factor activity. J Immunol 181: 1288-1298.

99. Van Neerven S, Kampmann E, Mey J (2008) RAR/RXR and PPAR/RXR signaling in neurological and psychiatric diseases. Prog Neurobiol 85: 433-451.

100. Chen JD, Evans RM (1995) A transcriptional co-repressor that interacts with nuclear hormone receptors. Nature 377: 454-457.

101. Shulman AI, Mangelsdorf DJ (2005) Retinoid x receptor heterodimers in the metabolic syndrome. N Engl J Med 353: 604-615.

102. Claudel T, Leibowitz MD, Fiévet C, Tailleux A, Wagner B, et al. (2001) Reduction of atherosclerosis in apolipoprotein $\mathrm{E}$ knockout mice by activation of the retinoid X receptor. Proc Natl Acad Sci U S A 98: 2610-2615.

103. Desreumaux P, Dubuquoy L, Nutten S, Peuchmaur M, Englaro W, et al. (2001) Attenuation of colon inflammation through activators of the retinoid X receptor (RXR)/peroxisome proliferator-activated receptor gamma (PPARgamma) heterodimer. A basis for new therapeutic strategies. J Exp Med 193: 827-838.

104. Yasmin R, Kannan-Thulasiraman P, Kagechika H, Dawson MI, Noy N (2010) Inhibition of mammary carcinoma cell growth by RXR is mediated by the receptor's oligomeric switch. J Mol Biol 397: 1121-1131.

105. Warrell RP, Jr., He LZ, Richon V, Calleja E, et al. (1998) Therapeutic targeting of transcription in acute promyelocytic leukemia by use of an inhibitor of histone deacetylase. J Natl Cancer Inst 90: 1621-1625.

106. Benoit GR (2001) Autonomous rexinoid death signaling is suppressed by converging signaling pathways in immature leukemia cells. Mol Endocrinol 15: 1154-1169. 